\title{
INFLUÊNCIA DAS CONCENTRAÇÕES DE ENZIMA E DE SUBSTRATO NO GRAU DE HIDRÓLISE E NO CONTEÚDO PROTÉICO DE HIDROLISADOS ENZIMÁTICOS DE CORVINA (Micropogonias furnieri)
}

\begin{abstract}
O objetivo deste trabalho foi avaliar como o grau de hidrólise $(\mathrm{GH})$ e o conteúdo protéico de hidrolisados enzimáticos de corvina podem sofrer influência da concentração de enzima e de substrato empregados na reação, utilizando metodologia de superfície de resposta (MSR). Os hidrolisados enzimáticos de pescado foram obtidos usando-se músculo de corvina como substrato, enzima Alcalase ${ }^{\circledR} 2.4 \mathrm{~L}, \mathrm{pH} 8,0$ e temperatura de reação de $50^{\circ} \mathrm{C}$. Após 60 minutos de reação, a enzima foi inativada por aquecimento do hidrolisado a $85^{\circ} \mathrm{C}$ por 15 minutos. Os hidrolisados inativados foram desidratados em estufa com circulação forçada de ar em temperatura de $60^{\circ} \mathrm{C}$ durante 10 horas. Os hidrolisados secos foram moídos em triturador de facas duplas, peneirados e acondicionados em recipientes herméticos em temperatura de refrigeração. Os resultados mostraram que a concentração de enzima influenciou significativamente o $\mathrm{GH}(\alpha=0,05)$ e o conteúdo protéico $(\alpha=0,10)$ dos hidrolisados e que a concentração de substrato apresentou influência significativa somente para os valores do conteúdo protéico dos mesmos.
\end{abstract}

PALAVRAS-CHAVE: CORVINA; HIDROLISADOS ENZIMÁTICOS; GRAU DE HIDRÓLISE; CONTEÚDO PROTÉICO; MSR.

* $\quad$ Mestranda em Engenharia de Alimentos, Fundação Universidade Federal do Rio Grande (FURG), Rio Grande, RS (e-mail: gracentenaro@yahoo.com.br).

** Doutora em Tecnologia de Alimentos, Professora do Departamento de Química, FURG, Rio Grande, RS (e-mail: mysame@yahoo.com). 


\section{INTRODUÇÃO}

O município de Rio Grande (RS), considerado área tradicional de captura de pescado, abriga diferentes indústrias pesqueiras que são responsáveis por parte do descarte de subprodutos da pesca (BRASIL, 2005). Alguns dos subprodutos do processamento são espécies de baixo valor comercial, destinadas para fabricação de farinha de pescado juntamente com os demais resíduos da indústria ou descartados no meio ambiente (KRISTINSSON e RASCO, 2000).

A recuperação e a modificação das proteínas do músculo de pescado, presentes no material proveniente dos subprodutos, e seu uso como ingrediente alimentício constitui uma alternativa muito promissora. Porém, para que a indústria desenvolva processos para recuperar e utilizar subprodutos é necessário que os mesmos sejam viáveis e melhores que o seu descarte. A hidrólise enzimática das proteínas de pescado tem sido usada como alternativa para converter biomassa subutilizada em produtos protéicos de consumo humano com elevado valor nutritivo e propriedades funcionais interessantes para elaboração de produtos alimentícios (DINIZ e MARTIN , 1997).

A modificação enzimática de proteínas, utilizando enzimas proteolíticas cada vez mais específicas, vem sendo amplamente estudada com o intuito de agregar valor ao pescado de baixo valor comercial, geralmente descartado pela indústria ou empregado para fins não-alimentícios (KRISTINSSON e RASCO, 2000). A concentração de enzima e de substrato são fatores importantes na cinética da reação e influem também na recuperação do produto. A especificidade da enzima determina principalmente a natureza do produto, podendo resultar em frações com diferentes pesos moleculares e conseqüentemente diferentes características funcionais. A natureza e o estado de desnaturação das proteínas do substrato são fatores determinantes na taxa de conversão da enzima, influenciando a natureza do produto. Assim, podem resultar peptídeos com diferentes tamanhos ou, até mesmo, aminoácidos livres em função da natureza e do estado do substrato (WHITAKER, 1994).

A hidrólise enzimática, realizada em condições brandas e controladas, garante a manutenção da qualidade nutricional dos hidrolisados e perfil peptídico definido. O grau de hidrólise $(G H)$ é o parâmetro utilizado para comparar os hidrolisados entre si. O conhecimento da relação entre o grau de hidrólise com alguma característica funcional específica do hidrolisado permite elaborar produtos com propriedades funcionais previamente definidas (KRISTINSSON, 2000a).

Neste trabalho estudou-se a influência da concentração de enzima e da concentração de substrato no grau de hidrólise e conteúdo protéico de hidrolisados enzimáticos de corvina.

\section{MATERIAL E MÉTODOS}

\subsection{MATÉRIA-PRIMA}

A matéria-prima utilizada para a obtenção dos hidrolisados foi a corvina (Micropogonias furnieri), espécie de baixo valor comercial, doada pela indústria PESCAL S.A, localizada na cidade de Rio Grande (RS).

\subsection{OBTENÇÃO DOS FILÉS E DA POLPA DE CORVINA}

O pescado foi transportado em recipiente com gelo até o Laboratório de Tecnologia de Alimentos da Fundação Universidade Federal do Rio Grande (FURG). Realizou-se pré-lavagem com o intuito de retirar as sujidades superficiais antes de iniciar a etapa de descabeçamento e evisceração. Essa ocorreu de modo que não houvesse contaminação do pescado pelas vísceras, seguida pela filetagem. Os filés limpos foram acondicionados em embalagens de polietileno e armazenados sob congelamento em freezer horizontal na temperatura de $-18^{\circ} \mathrm{C}$. Para realizar as reações enzimáticas, os filés foram descongelados e triturados em multiprocessador de facas duplas (Arno, modelo PL, "pic-liq") até a obtenção da carne moída denominada "polpa". 


\subsection{CARACTERIZAÇÃO DAMATÉRIA-PRIMA}

Os filés foram caracterizados fisicamente pela determinação de $\mathrm{pH}$, medido com potenciômetro de bancada (BRASIL, 1981), e o rendimento calculado a partir do peso dos filés obtidos em relação ao peso inicial do pescado. A composição proximal do filé de corvina foi determinada de acordo com a AOAC (1995), sendo proteínas pelo método de Kjeldahl ( $N$ x 6,25), lipídios pelo método de Soxhlet, cinzas pelo método gravimétrico em mufla $550-600^{\circ} \mathrm{C}$ e umidade pelo método gravimétrico em estufa $105^{\circ} \mathrm{C}$. Todos os valores foram obtidos em triplicata.

\subsection{OBTENÇÃO E CARACTERIZAÇÃO DOS HIDROLISADOS PROTÉICOS DE CORVINA}

Utilizou-se a enzima proteolítica Alcalase ${ }^{\circledR} 2.4$ L, fornecida pela Novozymes Latin América Ltda. Consultou-se a literatura científica para a determinação das faixas de trabalho, visando atingir graus de hidrólise adequados (sem prejudicar as características funcionais e nutricionais dos hidrolisados), obtendo-se hidrolisados nas faixas ótimas de $\mathrm{pH}$ e temperatura da enzima. Os hidrolisados foram caracterizados fisicamente pela determinação de rendimento. Foram determinados os teores de proteína e de umidade de acordo com a metodologia oficial da AOAC (1995), sendo a proteína pelo método de Kjeldahl $(\mathrm{N} \times 6,25)$ e a umidade pelo método gravimétrico em estufa $105^{\circ} \mathrm{C}$. Todos os valores foram obtidos em triplicata.

As reações enzimáticas foram realizadas com volume total de $800 \mathrm{~mL}$ em reator encamisado, usando-se agitador eixo-élice a $600 \mathrm{rpm}$ e temperatura de $50^{\circ} \mathrm{C}$ durante 60 minutos e pH ajustado com tampão fosfato pH 8,0 (MORITA e ASSUMPÇÃO 1976). Tomaram-se amostras no final da reação para a medida do grau de hidrólise de cada ensaio. Após o término da reação, a enzima foi inativada termicamente a $85^{\circ} \mathrm{C}$ durante 15 minutos. Os hidrolisados inativados foram desidratados em estufa com circulação forçada de ar (modelo Q314M, Quimis ${ }^{\circledR}$ ) em temperatura de $60^{\circ} \mathrm{C}$ durante 10 horas. Os hidrolisados secos foram moídos em multiprocessador de facas duplas (Arno, modelo PL "pic-liq"), peneirados e acondicionados em recipientes herméticos.

\subsubsection{Medida do Grau de Hidrólise}

Amostras de hidrolisados aos 60 minutos de reação foram tomadas para determinação do $\mathrm{GH}$, sendo a reação interrompida pela adição de solução de ácido tricloroacético (TCA 6,25\%) conforme PEZOA e MELLADO (1979). Após repouso de 15 minutos, a amostra foi filtrada em papel filtro (Whatman, $n^{\circ} 1$ ) e as proteínas solúveis medidas no filtrado pelo método de LOWRY et al. (1951), expressandose a concentração de proteínas como mg de albumina.

O grau de hidrólise foi expresso como a relação entre as proteínas solubilizadas e as proteínas totais presentes no substrato inicial, determinadas por Kjeldhal $(\mathrm{N} \times 6,25)$ de acordo com a equação 1:

$$
\% \mathrm{GH}=\frac{\text { mg proteína hidrolisada }}{\mathrm{mg} \text { proteína total }} \times 100 \quad \text { Equação }(1)
$$

\subsection{PLANEJAMENTO EXPERIMENTAL E TRATAMENTO ESTATÍSTICO}

Realizou-se planejamento experimental fatorial completo $2^{2}$ com três repetições no ponto central, duas variáveis de entrada estudadas em dois níves, totalizando onze ensaios (BARROS NETO, SCARMINIO e BRUNS, 1996). A Tabela 1 apresenta a matriz do planejamento com os respectivos valores codificados e reais. Como resposta avaliou-se o grau de hidrólise $(\mathrm{GH})$ e o rendimento em proteína ou conteúdo protéico dos hidrolisados. As variáveis independentes foram: concentração de 
substrato, sendo considerada a quantidade de proteína em relação ao volume de tampão (p/v); e a concentração de enzima, considerando a massa de enzima em relação à massa de proteínas presente no substrato $(p / p)$. Os dados experimentais foram analisados com o software Statistica versão 6.0 através de metodologia de superfície de resposta.

Primeiramente avaliaram-se os resultados dos ensaios lineares. Quando os modelos não se apresentaram preditivos, adicionaram-se os ensaios axiais para verificação dos modelos preditivos quadráticos. A influência da concentração de enzima e de substrato sobre o $\mathrm{GH}$ foi avaliada estatisticamente mediante análise de efeitos. Realizou-se análise de variância a fim de comparar os valores de $F$, considerando o modelo preditivo quando o valor de $F$ calculado foi no mínimo três vezes maior que $F$ tabelado. Obtiveram-se os modelos empíricos e as correspondentes superfícies de resposta.

\section{TABELA 1 - MATRIZ DO PLANEJAMENTO FATORIAL COMPLETO DO TIPO $2^{2}$ PARA A HIDRÓLISE ENZIMÁTICA DE CORVINA, UTILIZANDO ALCALASE $(\alpha= \pm 1,41)$}

\begin{tabular}{ccccc}
\hline Ensaio $^{a}$ & \multicolumn{3}{c}{ Valores codificados } & \multicolumn{2}{c}{ Valores reais } \\
\cline { 2 - 5 } 1 & {$[\mathrm{E}]$} & {$[\mathrm{S}]$} & {$[\mathrm{E}](\%, \mathrm{p} / \mathrm{p})$} & {$[\mathrm{S}](\%, \mathrm{p} / \mathrm{v})$} \\
2 & -1 & -1 & 0,04 & 3 \\
3 & +1 & -1 & 0,08 & 3 \\
4 & -1 & +1 & 0,04 & 7 \\
5 & +1 & +1 & 0,08 & 7 \\
6 & $-\alpha$ & 0 & 0,0318 & 5 \\
7 & $+\alpha$ & 0 & 0,0882 & 5 \\
8 & 0 & $-\alpha$ & 0,06 & 2,18 \\
9 & 0 & $+\alpha$ & 0,06 & 7,82 \\
10 & 0 & 0 & 0,06 & 5 \\
11 & 0 & 0 & 0,06 & 5 \\
\hline
\end{tabular}

a Experimentos realizados em ordem aleatória.

$[E]$ = concentração de enzima; $[S]$ = concentração de substrato.

\section{RESULTADOS E DISCUSSÃO}

\subsection{CARACTERIZAÇÃO DA MATÉRIA-PRIMA}

Os filés de corvina, utilizados como matéria-prima apresentaram valor de $\mathrm{pH}$ de $6,7( \pm 0,05)$, mostrando bom estado de conservação. Nesse sentido os resultados indicaram que o produto enquadrase na faixa normal de qualidade para esse parâmetro, considerando que os valores de $\mathrm{pH}$ para o pescado in natura não ultrapassaram o limite estipulado pela legislação brasileira (máximo de 6,8) (BRASIL, 1997).

De acordo com MARTIN (1982), o pH evidencia a qualidade do alimento, pois é afetado por reações que ocorrem após a morte do animal. Indica a presença de microrganismos que pelo seu metabolismo causam o acúmulo de material metabólico alcalino, que eleva o valor do $\mathrm{pH}$ e diminui a qualidade do produto. Na Tabela 2 estão apresentados os valores do rendimento de três exemplares de corvina, coletados para essa determinação.

A corvina apresentou rendimento médio de filés de $31,59 \% \pm 2,62$. Observou-se menor rendimento dessa espécie em relação ao atum, que de acordo com o trabalho desenvolvido por BRUSCHI (2001) apresentou rendimento em filés de $51,1 \%$. Durante o processamento no laboratório constatou-se 
dificuldade para a filetagem de corvina, devido à presença de ossos, espinhos e ao tamanho do pescado. Em função disso, parte do filé ficou aderida à pele diminuindo o rendimento final do mesmo. $O$ rendimento do filé depende da eficiência das máquinas filetadoras industriais e da destreza manual do operário, da forma anatômica do corpo, do tamanho da cabeça e peso das vísceras, pele e nadadeiras, como evidenciado por outros pesquisadores (CONTRERAS-GUZMÁN, 1994).

\section{TABELA 2 - RENDIMENTO DA MATÉRIA-PRIMA CORVINA (Micropogonias furnieri)}

\begin{tabular}{ccccc}
\hline Porção & Exemplar 1 (g) & Exemplar 2 (g) & Exemplar 3 (g) & Média \\
\hline Pescado inteiro & 1236,6 & 1433,1 & 1296,4 & 1322 \\
Pescado s/ cabeça & 841,2 & 1027,7 & 888,4 & 919,1 \\
Pescado s/ vísceras & 766,3 & 950,7 & 811,3 & 842,77 \\
Filé & 363,3 & 542,7 & 400,8 & 435,6 \\
Rendimento & 29,379 & 36,597 & 30,919 & $\mathbf{3 1 , 5 9 8}$ \\
\hline
\end{tabular}

\subsubsection{Composição Proximal dos Filés de Corvina}

A composição proximal dos filés de corvina, mostrada na Tabela 3, revelou valores para a matéria-prima in natura ligeiramente diferentes da literatura. A corvina é considerada espécie magra, no entanto, de acordo com YEANNES E ALMANDOS (2003) sua composição pode variar conforme os tecidos, sexo, idade do pescado e estação do ano.

TABELA 3 - COMPOSIÇÃO PROXIMAL DOS FILÉS DE CORVINA

\begin{tabular}{ccccc}
\hline & Umidade $(\%)$ & Proteínas $(\%)(N \times 6,25)$ & Lipídios $(\%)$ & Cinzas $(\%)$ \\
\hline Experimenta ${ }^{*}$ & $80,2 \pm 0,27$ & $18,1 \pm 0,28$ & $1,1 \pm 0,08$ & $0,70 \pm 0,10$ \\
Teórica & 76,4 & 19,4 & 1,6 & 1,2 \\
\hline
\end{tabular}

*( $\mu \pm 0 ́)$.

\subsubsection{Conteúdo de Umidade e Proteína dos Hidrolisados de Corvina}

Os valores de umidade e proteína apresentados pelos hidrolisados de corvina são mostrados na Tabela 4. Observou-se que os valores médios de umidade variaram na faixa de $7,2 \%$ a $13,1 \%$, sendo as diferenças devidas ao processo de secagem em estufa no qual se controla o tempo total de secagem e não a umidade final dos produtos. Tais valores são adequados para produtos em pó tipo farinha, cuja legislação permite umidade até $14 \%$ (BRASIL, 2007).

Os valores de conteúdo protéico variaram de $42,8 \%$ a $74,5 \%$ (b.u.). Observou-se, sem considerar a análise estatística, que valores elevados de proteína ( 73 a $80 \%$ b.s) foram obtidos para os hidrolisados 3,4 e 8 , produzidos pelas reações enzimáticas com maiores concentrações de substrato inicial. Por outro lado, valores de proteína menores que $57 \%$ (b.s.) foram obtidos para os hidrolisados 2 e $7 \mathrm{com}$ concentrações de substrato inicial igual ou menores que $3 \%$. Os valores de proteína encontrados estão de acordo com os relatados por NISANG et al. (2005), cujo hidrolisado protéico obtido a partir de concentrado de pescado apresentou $66,4 \%$ de proteínas e $7,24 \%$ de umidade. 
TABELA 4 - VALORES DE UMIDADE E PROTEÍNA DOS HIDROLISADOS DE CORVINA

\begin{tabular}{|c|c|c|c|}
\hline Ensaio & Umidade $(\%)^{a}$ & Proteína (\% b.u) ${ }^{a}(\mathrm{~N} \times 6,25)$ & $\begin{array}{c}\text { Proteína (\% b.s }{ }^{a} \\
(N \times 6,25)\end{array}$ \\
\hline 1 & $8,9 \pm 0,30$ & $69,4 \pm 0,20$ & $76,2 \pm 0,22$ \\
\hline 2 & $13,1 \pm 0,10$ & $42,8 \pm 0,20$ & $49,7 \pm 0,15$ \\
\hline 3 & $9,1 \pm 0,10$ & $71,7 \pm 0,20$ & $78,9 \pm 0,13$ \\
\hline 4 & $12,8 \pm 0,20$ & $63,7 \pm 0,30$ & $73,0 \pm 0,10$ \\
\hline 5 & $7,5 \pm 0,50$ & $69,6 \pm 0,40$ & $75,2 \pm 0,10$ \\
\hline 6 & $12,9 \pm 0,40$ & $49,1 \pm 0,10$ & $56,4 \pm 0,03$ \\
\hline 7 & $10,9 \pm 0,50$ & $51,0 \pm 0,10$ & $57,3 \pm 0,30$ \\
\hline 8 & $13,1 \pm 0,10$ & $69,0 \pm 0,10$ & $79,0 \pm 0,11$ \\
\hline 9 & $7,3 \pm 0,30$ & $73,2 \pm 0,20$ & $78,9 \pm 0,03$ \\
\hline 10 & $7,2 \pm 0,10$ & $74,5 \pm 0,25$ & $80,3 \pm 0,20$ \\
\hline 11 & $7,8 \pm 0,60$ & $69,1 \pm 0,05$ & $74,9 \pm 0,20$ \\
\hline
\end{tabular}

a valor médio de três repetições.

\subsection{GRAU DE HIDRÓLISE E CONTEÚDO PROTÉICO}

Os resultados de $\mathrm{GH}$ e de conteúdo protéico para os hidrolisados obtidos a partir de corvina estão apresentados na Tabela 5.

TABELA 5 - GRAU DE HIDRÓLISE E CONTEÚDO PROTÉICO (N X 6,25) DOS HIDROLISADOS DE CORVINA

\begin{tabular}{|c|c|c|c|c|c|c|}
\hline \multirow{2}{*}{ Ensaio $^{a}$} & \multicolumn{2}{|c|}{$\begin{array}{c}\text { Valores } \\
\text { codificados }\end{array}$} & \multicolumn{2}{|c|}{$\begin{array}{c}\text { Valores } \\
\text { reais }\end{array}$} & \multicolumn{2}{|c|}{ Respostas $^{b}$} \\
\hline & $x_{1}$ & $x_{2}$ & $\begin{array}{c}{[E]} \\
(\%, p / p)\end{array}$ & $\begin{array}{c}{[\mathrm{S}]} \\
(\%, \mathrm{p} / \mathrm{r})\end{array}$ & $\% \mathrm{GH}$ & $\begin{array}{c}\text { Cont. Protéico } \\
(\% \text { b.u })\end{array}$ \\
\hline 1 & -1 & -1 & 0,04 & 3 & $14,0 \pm 0,75$ & $69,4 \pm 0,20$ \\
\hline 2 & +1 & -1 & 0,08 & 3 & $40,6 \pm 0,89$ & $42,8 \pm 0,20$ \\
\hline 3 & -1 & +1 & 0,04 & 7 & $19,8 \pm 0,21$ & $71,7 \pm 0,20$ \\
\hline 4 & +1 & +1 & 0,08 & 7 & $30,8 \pm 0,84$ & $63,7 \pm 0,30$ \\
\hline 5 & $-1,41$ & 0 & 0,0318 & 5 & $15,7 \pm 0,26$ & $69,6 \pm 0,40$ \\
\hline 6 & $+1,41$ & 0 & 0,0882 & 5 & $37,7 \pm 0,79$ & $49,1 \pm 0,10$ \\
\hline 7 & 0 & $-1,41$ & 0,06 & 2,18 & $12,2 \pm 0,11$ & $51,0 \pm 0,10$ \\
\hline 8 & 0 & $+1,41$ & 0,06 & 7,82 & $43,7 \pm 0,33$ & $69,0 \pm 0,10$ \\
\hline 9 & 0 & 0 & 0,06 & 5 & $15,0 \pm 0,45$ & $73,2 \pm 0,20$ \\
\hline 10 & 0 & 0 & 0,06 & 5 & $15,3 \pm 0,28$ & $74,5 \pm 0.25$ \\
\hline 11 & 0 & 0 & 0,06 & 5 & $15,1 \pm 0,25$ & $69,1 \pm 0,05$ \\
\hline
\end{tabular}

${ }^{a}$ Experimentos realizados em ordem aleatória.

${ }^{b}$ Valor médio para três repetições.

$[E]=$ concentração de enzima; $[S]$ = concentração de substrato.

O GH apresentou variação de $12,2 \%$ a $43,7 \%$ nos ensaios 7 e 8 , respectivamente. A análise estatística dos resultados mostrou que a concentração de enzima apresentou efeito significativo nas respostas do GH (Tabela 6). De acordo com KRISTINSSON e RASCO (2000b) a elevação da concentração de proteases aumenta o grau de hidrólise, embora os custos do processo também se elevem em função da utilização de maiores volumes desse produto. 
As concentrações de substrato e de enzima apresentaram efeito significativo no processo. Quando se eleva a concentração de enzima no meio de 0,04 para $0,08 \%$ ocorre aumento de $18,78 \%$ no $\mathrm{GH}$. Já para a concentração de substrato observou-se efeito negativo no aumento do GH quando sua concentração no meio passou de 3 para $7 \%$, significando diminuição de 2,02\%. A interação entre as variáveis [E] e [S] influenciaram negativamente o GH, causando diminuição de 7,85\%.

\section{TABELA 6 - EFEITOS ESTIMADOS PARA O GH DOS HIDROLISADOS PROTÉICOS DE CORVINA OBTIDOS COM ALCALASE}

\begin{tabular}{ccccc}
\hline Variáveis & Efeitos & Erro-padrẫo & Valor t & Valor $p$ \\
\hline Média & 21,53143 & 0,043807 & 491,5073 & $0,000004^{*}$ \\
[E] (L) & 18,78500 & 0,115902 & 162,0762 & $0,000038^{*}$ \\
[S](L) & $-2,02500$ & 0,115902 & $-17,4716$ & $0,003260^{*}$ \\
[E] x[S] & $-7,81500$ & 0,115902 & $-67,4275$ & $0,000220^{*}$ \\
\hline
\end{tabular}

*significativos $(p<0,05)$.

$[E]=$ concentração de enzima; $[\mathrm{S}]$ = concentração de substrato.

A análise dos resultados mostrou que o planejamento experimental realizado para obtenção dos hidrolisados protéicos de corvina, a partir da enzima Alcalase, não apresentou modelo preditivo para o $\mathrm{GH}$, visto que o valor de $\mathrm{F}$ calculado não foi suficientemente maior que o tabelado. Isso não torna os resultados inválidos, pois aumentando a concentração de enzima é possível elevar os valores de GH e diminuindo as concentrações dessa variável pode-se obter menores valores de GH. Assim, seria possível obter hidrolisados com ampla faixa de grau de hidrólise visto que algumas propriedades funcionais importantes das proteínas dependem de diferentes valores de $\mathrm{GH}$.

Para VENUGOPAL e SHAHIDI (1995), a escolha da enzima e das condições de processamento determinam as propriedades do produto. Condições brandas como períodos curtos de hidrólise e temperaturas moderadas são importantes para obter propriedades emulsificantes e geleificantes.

Hidrólise não-controlada pode produzir peptídeos de cadeia curta com perda das propriedades funcionais das proteínas nativas e contribuir para o surgimento de gosto amargo nos produtos obtidos. Por isso, o grau de hidrólise destaca-se na otimização dos parâmetros de processo no desenvolvimento de determinados produtos.

Para o conteúdo protéico, apresentado como resposta do planejamento realizado, foi observada variação de $42,8 \%$ para $74,5 \%$ (b.u) nos ensaios 2 e 10 , respectivamente. Verificou-se que quando a concentração de enzima aumentou de $0,04 \%$ para $0,08 \%$, como mostrado na Tabela 7 , houve efeito negativo no rendimento do conteúdo protéico dos hidrolisados (diminuição de 17,3\%). Os ensaios 9 , 10 e 11 apresentaram maiores rendimentos em proteína em relação à maioria dos demais hidrolisados. Portanto, o emprego desse sistema enzimático pode ser útil quando se pretende obter produto com reduzido $\mathrm{GH}$.

A análise estatística dos resultados do conteúdo protéico dos hidrolisados revelou que a concentração de substrato é de fundamental importância para o GH. Fato verificado por BENJAKUL e MORRISSEY (1997) que por meio da hidrólise de resíduo de merluza (Merluccius productus), a partir de Alcalase, obtiveram conteúdo protéico em maiores concentrações de substrato. Mas LINDER et al. (1995), citados por KRISTINSSON E RASCO (2000b), verificaram que quando são empregadas concentrações maiores que $8 \%$ no sistema sem considerar a enzima, a concentração de substrato poderá apresentar efeito inibidor na recuperação das proteínas. A interação entre as variáveis [E] e [S] causou aumento de 9,3\% no conteúdo protéico. 
TABELA 7 - EFEITOS ESTIMADOS PARA O CONTEÚDO PROTÉICO DOS HIDROLISADOS PROTÉICOS DE CORVINA OBTIDOS COM ALCALASE

\begin{tabular}{ccccc}
\hline Variáveis & Efeitos & Erro-padrẫo & Valor t & Valor p \\
\hline Média & 66,3429 & 1,065252 & 62,27902 & $0,000258^{*}$ \\
[E] & $-17,3000$ & 2,818392 & $-6,13825$ & $0,025529^{*}$ \\
[S] & 11,6000 & 2,818392 & 4,11582 & $0,054271^{*}$ \\
Interaçẫo & 9,3000 & 2,818392 & 3,29975 & $0,080858^{*}$ \\
\hline
\end{tabular}

${ }^{*}$ significativos $(p<0,10)$.

$[E]=$ concentração de enzima; $[S]$ = concentração de substrato.

Considerando os efeitos significativos $(\alpha=0,10 \%)$ buscou-se o coeficiente de determinação do modelo matemático $\left(R^{2}=0,9744\right)$ e a respectiva equação desenvolvida para predizer o conteúdo protéico dos hidrolisados. A análise de variância, apresentada na Tabela 8 , mostrou que o modelo quadrático se ajustou bem aos dados experimentais quanto ao conteúdo protéico.

TABELA 8 - ANÁLISE DE VARIÂNCIA DOS VALORES DE CONTEÚDO PROTÉICO DOS HIDROLISADOS DE CORVINA

\begin{tabular}{ccccc}
\hline Fonte de variaçẫo & SQ & GL & MQ & F \\
\hline Regressắo & 1175,291 & 5 & 235,05 & 30,09 \\
Resíduo & 30,885 & 5 & 6,177 & \\
Falta de Ajuste & 14,998 & 34 & & \\
Erro Puro & 15,887 & 2 & & \\
Total & 1206,176 & 10 & & \\
\hline
\end{tabular}

$S Q=$ soma quadrática; $G L=$ graus de liberdade; $M Q=$ média quadrática; $F$ = teste de Fisher. $\mathrm{F}$ tabelado $=3,45$.

Coeficiente de determinação $\mathrm{R}^{2}=0,9744$.

Obteve-se modelo preditivo, visto que o $\mathrm{F}$ calculado $(13,91)$ foi suficientemente superior ao $\mathrm{F}$ tabelado $(3,45)$. Na Tabela 9 estão apresentados os coeficientes de regressão, utilizados para a construção do modelo matemático que relaciona o conteúdo protéico com as variáveis concentração de enzima e concentração de substrato.

TABELA 9 - COEFICIENTES DE REGRESSÃO DO CONTEÚDO PROTÉICO DOS HIDROLISADOS DE CORVINA OBTIDOS COM ALCALASE

\begin{tabular}{|c|c|c|c|c|c|c|}
\hline Variáveis & $\begin{array}{c}\text { Coef.de } \\
\text { Regressẫo }\end{array}$ & $\begin{array}{l}\text { Erro- } \\
\text { padrấo }\end{array}$ & $t(2)$ & $p$ & $\begin{array}{c}\text { Lim. Conf. } \\
-90 \%\end{array}$ & $\begin{array}{l}\text { Lim. Conf. } \\
+90 \%\end{array}$ \\
\hline $\begin{array}{l}\text { Média } \\
{[\mathrm{E}](\mathrm{L})} \\
{[\mathrm{E}](\mathrm{Q})} \\
{[\mathrm{S}](\mathrm{L})} \\
{[\mathrm{S}](\mathrm{O})} \\
{[\mathrm{E}] \times[\mathrm{S}]}\end{array}$ & $\begin{array}{c}72,25754 \\
-7,96181 \\
-5,91389 \\
6,09062 \\
-5,58695 \\
4,65000\end{array}$ & $\begin{array}{l}1,627180 \\
0,997938 \\
1,190799 \\
0,997938 \\
1,190799 \\
1,409196\end{array}$ & $\begin{array}{c}44,40661 \\
-7,97827 \\
-4,96632 \\
6,10321 \\
-4,69176 \\
3,29975\end{array}$ & $\begin{array}{l}0,000507^{*} \\
0,015349^{*} \\
0,038234^{*} \\
0,025811^{*} \\
0,042550^{*} \\
0,080858^{*}\end{array}$ & $\begin{array}{r}65,256 \\
-12,255 \\
-11,037 \\
1,7968 \\
-10,710 \\
-1,4133 \\
\end{array}$ & $\begin{array}{l}79,2587 \\
-3,6680 \\
-0,7902 \\
10,3844 \\
-0,4633 \\
10,7132 \\
\end{array}$ \\
\hline
\end{tabular}

* significativos $(p<0,10)$.

$[E]=$ concentração de enzima; $[S]$ = concentração de substrato.

O modelo com as variáveis codificadas, que representa a concentração do conteúdo protéico em função da concentração de enzima e concentração de substrato na faixa estudada, está representado pela equação 2 : 
O modelo utilizado na construção das linhas de contorno (Figura 1) permite verificar que a região em que se pode obter o maior conteúdo protéico (em torno de $74,5 \%$ ) encontra-se no nível de concentração de enzima de 0,04 a 006\% e concentração de substrato entre e 5 e $7 \%$.

\section{FIGURA 1 - LINHAS DE CONTORNO REPRESENTANDO O CONTEÚDO PROTÉICO DOS HIDROLISADOS DE CORVINA EM FUNÇÃO DA CONCENTRAÇÃO DE ENZIMA E DE SUBSTRATO}

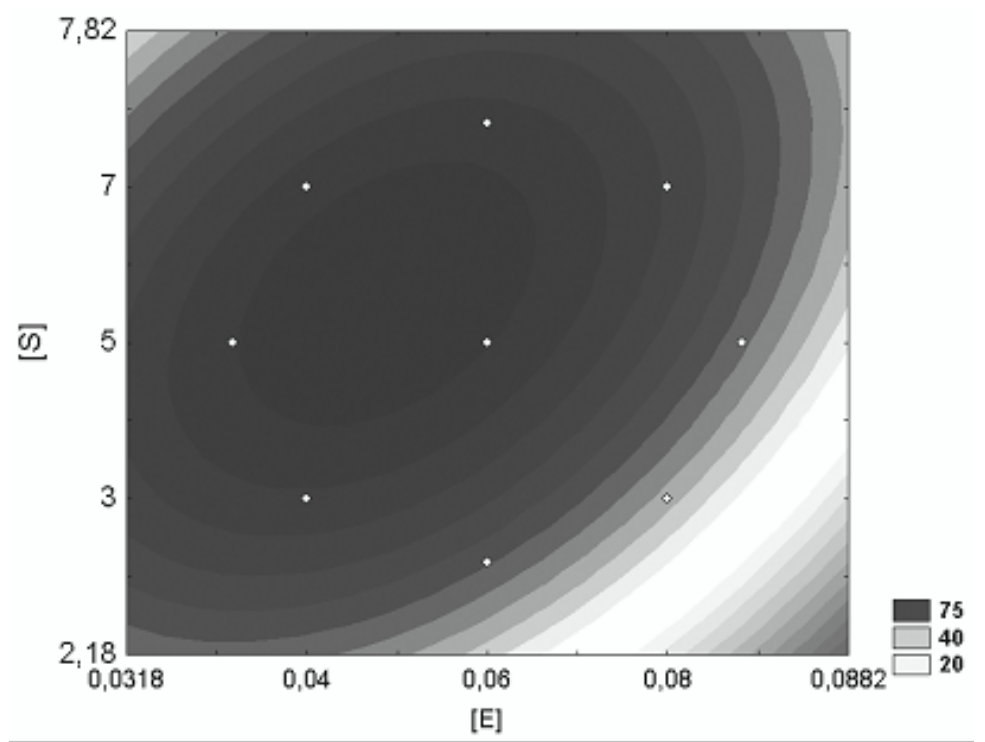

4 CONCLUSÃO

Foram obtidos hidrolisados protéicos com diferentes graus de hidrólise e conteúdos protéicos a partir de corvina, usando Alcalase 2.4L. As concentrações de enzima e de substrato influenciaram significativamente o grau de hidrólise e o conteúdo protéico dos hidrolisados.

A concentração de enzima influiu positivamente no grau de hidrólise e negativamente no conteúdo protéico. Já a concentração de substrato influiu negativamente no grau de hidrólise e positivamente no conteúdo protéico.

A interação das variáveis concentrações de enzima e concentração de substrato influenciou negativamente o grau de hidrólise, não apresentando efeito significativo no conteúdo protéico.

\section{ABSTRACT}

INFLUENCE OF SUBSTRATE AND ENZYME CONCENTRATIONS ON THE HYDROLYSIS DEGREE AND PROTEIN CONTENT OF CORVINA (Micropogonias furnieri) ENZYMATIC HYDROLYSATES

The aim of this work was to evaluate how the hydrolysis degree (HD) and protein content of hydrolysates of croaker might be influenced by enzyme and substrate concentrations of reaction utilizing Response Surface Methodology (RSM). The enzymatic hydolysates of fish were obtained in the following conditions: the substrate was croacker muscle, the enzyme was Alcalase ${ }^{\circledR} 2.4 \mathrm{~L}, \mathrm{pH}$ value 8,0 and reaction temperature of $50^{\circ} \mathrm{C}$. After 60 minutes the enzyme was inactivated by heating the hydrolysates at $85^{\circ} \mathrm{C}$ for 15 minutes. Then the hydrolysates were dried, milled and conditioned in hermetic recipients. Results showed that the enzyme concentration influenced significantly the $\mathrm{GH}(\alpha=0,05)$ and the protein content $(\alpha=0,10)$ of hydrolysates and the substrate concentration presented only a significant influence over the protein content values of the hydrolysates. 


\section{REFERÊNCIAS}

AOAC. Association of Official Analytical Chemists. Official methods of analysis of AOAC international. $16^{\text {th }}$ ed. Arlington, 1995.

BARROS NETO, B.; SCARMINIO, I. S.; BRUNS, R. E. Planejamento e otimização de experimentos. 2. ed. São Paulo: Editora da Unicamp, 1996.

BENJAKUL, B.; MORRISSEY, M. T. Protein hydrolysates from Pacific whiting solid waste. Journal of Agricultural and Food Chemistry, v. 45, p. 3424-3430, 1997.

BRASIL. Ministério da Agricultura. Secretaria Nacional de Defesa Agropecuária. Laboratório Nacional de Referência Animal. Métodos analíticos oficiais para controle de produtos de origem animal e seus ingredientes: II - Métodos físicos e químicos. Brasília, 1981.

BRASIL. Ministério da Agricultura, Pecuária e Abastecimento. Secretaria de Defesa Agropecuária. Portaria $n^{\circ} 185$ de 13 de maio de 1997. Regulamento técnico de identidade e qualidade de peixe fresco (inteiro e eviscerado). Disponível em: <http:// www.agricultura.gov.br/> Acesso em: 28 de março de 2007.

BRASIL. Agência Nacional de Vigilância Sanitária. Regulamento técnico referente à farinha de trigo. Portaria № 354, de 18 de julho de 1996. Disponível em:<http://www.anvisa.gov.br/>. Acesso em: 2 de fevereiro de 2007.

BRASIL. Ministério da Agricultura. Secretaria Municipal do Instituto Brasileiro do Meio Ambiente e dos Recursos Naturais Renováveis. Desembarque de Pescado no Rio Grande do Sul em 2004. Rio Grande, 2005.

BRUSCHI, F. L. F. Rendimento, composição química e perfil de ácidos graxos de pescados e seus resíduos: uma comparação. Itajaí, 2001. 65 p. Trabalho de Conclusão de Curso (Graduação em Oceanografia), Universidade do Vale do Itajaí.

CONTRERAS-GUZMÁN, E. S. Bioquímica de pescados e derivados. Jaboticabal: FUNEP,1994.

DINIZ, F. M.; MARTIN, A. M. Optimization of nitrogen recovery in the enzymatic hydrolysis of dogfish (Squalus acanthias) protein. Composition of the hydrolysates. International Journal of Food Science and Nutrition, $v$. 48, p.191-200, 1997.

KRISTINSSON, H. G.; RASCO, B. A. Kinetic of the hydrolysis of atlantic salmon (Salmo salar) muscle proteins by alkaline proteases and a visceral serine protein. Process Biochem., v.36, p.131-39, 2000a.

KRISTINSSON, H. G.; RASCO, B. A. Fish protein hydrolysates: production, biochemical and functional properties. Critical Reviews in Food Science and Nutrition, Washington, v.40, n. 1, p. 43-81, 2000b.

LOWRY, O. H.; ROSEBROUGH, N. J.; FARR, A. L.; RANDALL, R. J. Protein measurement with the Folin phenol reagent. Journal Biol. Chem., v.193, p. 265-275, 1951.

MORITA, T.; ASSUMPÇÃO, R. M. V. Manual de soluções, reagentes e solventes. São Paulo: Edgard Blücher, 1976. p. 272.

MARTIN, R. E. Chemistry and biochemistry of marine food products. Westport: AVI Publishing, 1982.

NISANG, S.; LERTSIRI, S.; SUPHANTHARIKA, M.; ASSAVANING, A. Optimization of enzymatic hydrolysis of fish soluble concentrate by commercial proteases. Journal of Food Engineering, v. 70, p. 571-578, 2005.

PEZOA, V. G.; MELLADO, M. S. Estudo das condições ótimas de pH e temperatura para atividade enzimática de estratos dos componentes do aparelho digestivo de corvina (Micropogon furnieri) e castanha (Umbrina canosai). In: . Obtenção de um concentrado de proteínas de pescado para alimentos pelo método enzimático, utilizando as próprias enzimas do pescado. Rio Grande: Editora FURG, 1979. p. 5-38.

VENUGOPAL, V.; SHAHIDI, F. Value-added products from underutilized fish species. Critical Reviews in Food Science and Nutrition, v. 35, p. 431-453, 1995.

YEANNES, M. I.; ALMANDOS, M.E. Estimation of fish proximate composition starting from water contend. Journal of Food Composition and Analysis, v. 16, p. 81-92, 2003.

WHITAKER, R. Principles of enzymology for food science. New York: Marcel Decker, 1994. 